\title{
Polyphenols from the Rhizomes of Potentilla freyniana
}

\section{Xiao-Hui $\mathrm{Wu}^{1 *}$, Chao $\mathrm{Mi}^{2}$, Yi He${ }^{1}$, Shu-Qing Wang${ }^{1}$, Jun Zhang ${ }^{1}$ and Yan-Wen Zhang ${ }^{1 *}$}

${ }^{1}$ Tianjin Key Laboratory on Technologies Enabling Development of Clinical, Therapeutics and Diagnostics, College of Pharmacy, Tianjin Medical University, Tianjin 300070, China

${ }^{2}$ College of Public Health and Communication, Tianjin Medical University, Tianjin 300070, China

\author{
Abstract \\ A new polyphenol, Potentillanin A (1), together with two known compounds (2-3), was isolated from the chloroform \\ soluble fraction of Potentilla freyniana. The structure of Potentillanin A (1) was elucidated by spectroscopic methods.
}

Keywords: Potentilla freyniana; Potentillanin A; Polyphenols; Spectroscopic methods

\section{Introduction}

The rhizomes of Potentilla freyniana Borum in traditional Chinese medicine (TCM) are a source of Chinese folk drug "Wei-ling-Cai", and are supposed to be effective as relieving pain and anti-inflammatory in folklore medicine [1]. It's curative effect is well and adverse reaction is little. In the previous paper, only $\beta$-sitosterol and daucosterol were reported from this plant [2]. In the current research, a new polyphenol Potentillanin A (1), together with known compounds (2-3) was isolated from the rhizomes of $P$. freyniana. The structure of 1 was elucidated mainly by NMR techniques. Herein, we report the isolation and structure elucidation of these polyphenols.

\section{Experimental}

\section{General experimental procedures}

IR spectra were recorded with a Perkin-Elmer 577 spectrometer as $\mathrm{KBr}$ pellet. NMR spectra were recorded with a Bruker AM-400 spectrometer with TMS as an internal standard. EI-MS $(70 \mathrm{eV})$ was carried out with a Finnigan MAT 95 mass spectrometer. CD spectra were recorded on a JASCO J-810 spectropolarimeter. All solvents used were of analytical grade (Shanghai Chemical Plant). Silica gel (200 300 mesh) $\mathrm{C}_{18}$ reversed-phase silica gel $(150$ - 200 mesh, Merck) etc. were used for column chromatography, and pre-coated silica gel $\mathrm{GF}_{254}$ plate (QingDao Marine Chemical Plant) was used for TLC.

\section{Plant material}

The rhizomes of Potentilla freyniana were collected in July 2005 from Enshi County of Hubei Province, People's Republic of China, and identified by Prof. Changgong Zhang, College of Pharmacy, Tongji Medical Center, Huangzhong University of Science and Technology. A specimen (DFZ0120) was deposited in the College of Pharmacy, Tongji Medical Center, Huangzhong University of Science and Technology.

\section{Extraction and isolation}

The air-dried rhizomes of $P$. freyniana $(5.0 \mathrm{~kg})$ were ground and extracted with $95 \%$ ethanol $(10 \times 5 \mathrm{~L})$ at room temperature. The ethanol extract was concentrated under vacuum to leave a residue, which was suspended in $\mathrm{H}_{2} \mathrm{O}(3 \mathrm{~L})$ and extracted with Petroleum ether $(3 \times 3 \mathrm{~L}), \mathrm{CHCl}_{3}(3 \times 3 \mathrm{~L})$, EtOAc $(3 \times 3 \mathrm{~L})$, and $n-\mathrm{BuOH}(3$ $\times 3 \mathrm{~L})$, sequentially. A part of the $\mathrm{CHCl}_{3}$ extract $(20 \mathrm{~g})$ was subjected to a silica gel column chromatography eluting with gradient solvents of Petroleum ether - Acetone (15:1 - 1:1, and then pure Acetone) to afford four fractions (Fr. 1 - 4). Fraction 2 was chromatographed over silica gel eluting with $\mathrm{CHCl}_{3}$-EtOAc (8:1) to yield $15 \mathrm{mg}$ of $1(0.0003$ $\%$, w/w) $\left(R f=0.5\right.$, developed with $\mathrm{CHCl}_{3}$-EtOAc (6:1) $)$. Fraction 3 was chromatographied over silica gel eluting with $\mathrm{CHCl}_{3}$-Acetone (5:1) to afford $2(20 \mathrm{mg}, 0.0004 \%, \mathrm{w} / \mathrm{w})$ and $3(35 \mathrm{mg}, 0.0007 \%$, w/w).
Potentillanin $\mathrm{A}(1) \mathrm{C}_{11} \mathrm{H}_{14} \mathrm{O}_{5}$ an amorphous powder, $[\alpha]_{\mathrm{D}}{ }^{20}:+79.0^{\circ}$ (MeOH, $c 0.20)$. CD (c 0.0038, MeOH), IR(KBr): $v_{\max } \mathrm{cm}^{-1}: 3438,2251$, 1653, 1027. ${ }^{1} \mathrm{H}-\mathrm{NMR}(400 \mathrm{MHz})$ and ${ }^{13} \mathrm{C}-\mathrm{NMR}(100 \mathrm{MHz})$ (Table 1). EI-MS (70eV): m/z: 227 (2), 226 (40), 180 (15), 152 (10), 139 (100), 84 (50), 66 (65); positive HREIMS : $m / z 226.0839[\mathrm{M}]^{+}\left(\mathrm{C}_{11} \mathrm{H}_{14} \mathrm{O}_{5}\right.$, Calcd 226.0841).

\section{Results and Discussion}

Potentillanin A (1), an amorphous powder, showed molecular formula of $\mathrm{C}_{11} \mathrm{H}_{14} \mathrm{O}_{5}$ determined on the basis of positive HREIMS at $\mathrm{m} / \mathrm{z} 226.0839[\mathrm{M}]^{+}$(Calcd 226.0841) with $5^{\circ}$ of unsaturation. Eleven carbon signals including one methyl, two methylenes, four methines, four quaternary carbons were evident from the ${ }^{13} \mathrm{C}-\mathrm{NMR}$ spectra of 1 (Table 1). The IR spectrum showed absorptions at 3438, 1653, and 1027 $\mathrm{cm}^{-1}$ representing the existence of hydroxyl, benzene ring and ether linkage group, respectively. In the ${ }^{13} \mathrm{C}-\mathrm{NMR}$ spectrum, one oxygenated methylene $\left(\delta 63.5, \mathrm{C}-1^{\prime}\right)$, one ketal carbon $(\delta 98.1, \mathrm{C}-2)$, one oxygenated methine carbon $(\delta 63.1, \mathrm{C}-3)$ and three oxygenated quaternary carbons

\begin{tabular}{|c|c|c|}
\hline $\mathbf{N O}$ & $\boldsymbol{\delta}_{\mathbf{c}}$ & $\boldsymbol{\delta}_{\mathbf{H}}, \mathbf{M u l t i}, \boldsymbol{J}(\mathbf{H z})$ \\
\hline 1 & - & - \\
\hline 2 & 99.1 & $4.87(\mathrm{~d}, 2.4)$ \\
\hline 3 & 63.2 & $3.74(\mathrm{~m})$ \\
\hline 4 & 23.9 & $2.42(2 \mathrm{H}, \mathrm{m})$ \\
\hline 5 & 156.7 & - \\
\hline 6 & 95.9 & $5.89(\mathrm{~d}, 1.6)$ \\
\hline 7 & 157.0 & - \\
\hline 8 & 94.9 & $5.68(\mathrm{~d}, 1.6)$ \\
\hline 9 & 152.7 & - \\
\hline 10 & 98.8 & - \\
\hline 1 & 63.6 & $3.59(\mathrm{~m})$ \\
\hline & & $1.08(\mathrm{t}, 6.8)$ \\
\hline 2 & 15.6 & \\
\hline
\end{tabular}

Table 1: ${ }^{1} \mathrm{H}-\mathrm{NMR}(400 \mathrm{MHz})$ and ${ }^{13} \mathrm{C}-\mathrm{NMR}(100 \mathrm{MHz})$ spectral data of 1 (in DMSO- $d_{6}$ ).

*Corresponding authors: Xiao-Hui Wu, Yan-Wen Zhang, Tianjin Key Laboratory on Technologies Enabling Development of Clinical, Therapeutics and Diagnostics, College of Pharmacy, Tianjin Medical University, Tianjin 300070, China, Tel.: +86-22-60357206; Fax: +86-22-60357208; E-mail: Ionghui804@163.com, zhangyanwen@tijmu.edu.cn

Received December 11, 2014; Accepted January 09, 2015; Published January 12,2015

Citation: Wu XH, Mi C, He Y, Wang SQ, Zhang J, et al. (2015) Polyphenols from the Rhizomes of Potentilla freyniana. Med chem 5: 015-020. doi:10.4172/21610444.1000237

Copyright: ( $2015 \mathrm{Wu} \mathrm{XH}$, et al. This is an open-access article distributed under the terms of the Creative Commons Attribution License, which permits unrestricted use, distribution, and reproduction in any medium, provided the original author and source are credited. 
Citation: Wu XH, Mi C, He Y, Wang SQ, Zhang J, et al. (2015) Polyphenols from the Rhizomes of Potentilla freyniana. Med chem 5: 021-022. doi:10.4172/2161-0444.1000237

( $\delta$ 156.7, C-5; $\delta 157.0, \mathrm{C}-7 ; \delta 152.7, \mathrm{C}-9$ ). A benzene ring and the presence of a cyclic system accounted for $5^{\circ}$ of the unsaturation. The ${ }^{1} \mathrm{H}-\mathrm{NMR}$ spectrum (in DMSO- $d_{6}$ ) of 1 (table 1 ) displayed one methyl signal at $1.08\left(\mathrm{t}, J=6.8, \mathrm{CH}_{3}-2^{\prime}\right)$, two oxygenated methylene protons at $\delta 3.59$ and $\delta 3.68\left(\mathrm{~m}, \mathrm{CH}_{2}-1^{\prime}\right)$, one ketal carbon proton at $\delta 4.87$ $(\mathrm{d}, J=2.4, \mathrm{H}-2)$, one oxygenated methine proton at $\delta 3.74(\mathrm{~m}, \mathrm{H}-3)$, two methylene protons at $\delta 2.42\left(\mathrm{~m}, \mathrm{CH}_{2}-4\right)$, two methine protons at $\delta 5.89(\mathrm{~d}, J=1.6, \mathrm{H}-6)$ and $\delta 5.68(\mathrm{~d}, J=1.6, \mathrm{H}-8)$. The coupling and oxygenated patterns revealed by ${ }^{1} \mathrm{H}-\mathrm{NMR}$ were consistent with the functional groups indicated by the above ${ }^{13} \mathrm{C}-\mathrm{NMR}$ analyses.

Analysis of the ${ }^{1} \mathrm{H}-\mathrm{NMR},{ }^{13} \mathrm{C}-\mathrm{NMR}$ and HSQC spectra of 1 enabled the assignment of all the protons to the bonding carbons. The HMBC correlations and planar structure of 1 was outlined as Figure 1.

The structure is similar to character of a flavan-3-ol, and its CD spectrum (Figure 2) is consistent with that of a flavan-3-ol. It showed a strong positive effect near $270 \mathrm{~nm}$, and a negative effect near $290 \mathrm{~nm}$. Analysis of the CD spectrum, the stereochemical structure was fit to

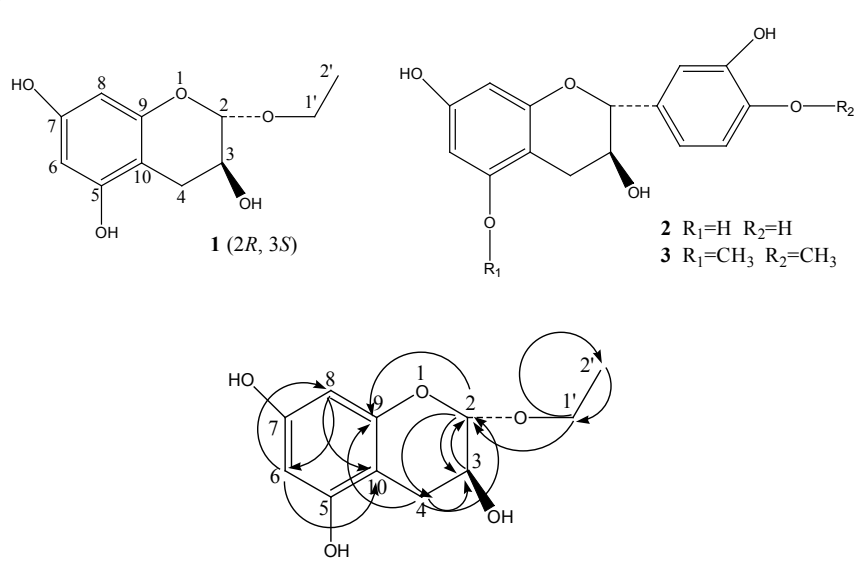

Figure 1: The HMBC correlations $(H \rightarrow C)$ of $1 \lambda[n m]$.

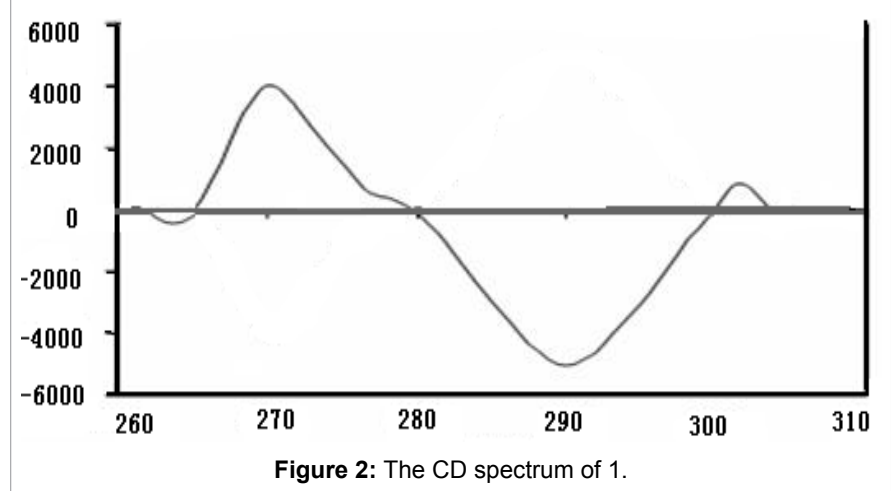

be $(2 R, 3 S)$ refered to [3]. Thus, the structure of 1 was unambiguously elucidated as $(2 R, 3 S)$ - 2 - ethoxy - 3,5,7 - trihydroxy - 3,4 - dihydro Benzopyran (1).

The two known polyphenols were successively identified as 2 refered to [4], and 3 refered to [5] on the basis of EI-MS, ${ }^{1} \mathrm{H}-\mathrm{NMR}$ and ${ }^{13} \mathrm{C}$-NMR data. The compounds 2 and 3 were isolated from this plant for the first time.

\section{Acknowledgements}

Special thanks are due to the Analytical Center, Huazhong University of Science and Technology for recording UV, MS, CD and NMR spectra.

\section{References}

1. Xie ZW, Yu YC (1989) Index Chinese Traditional and Herbal Drugs. Beijing People's Medical Publishing House.

2. Cai YH, Liu L, Han DX, Liu CL (2005) Wuhan Ligong Daxue Xuebao 27: 32.

3. Slade D, Ferreira D, Marais JPJ (2005) Circular dichroism, a powerful tool for the assessment of absolute configuration of flavonoids. Phytochemistry 66: 2177-2215.

4. Ma CM, Jia SS, Sun T, Zhang YW (1993) Acta Pharm Sin 28: 152.

5. Yoshiki K, Genichiro N, Itsuo N (1986) Chem Pharm Bull 34: 3208. 